1 Department of Politics, University of York, York, UK

2 Department of Political Science, University of Pittsburgh, Pittsburgh, PA, USA

Correspondence to: A Moore alfred.moore@york.ac.uk Cite this as: $B M J \$\{y e a r\} ; 371: m 4039$ http://dx.doi.org/10.1136/bmj.m4039 Published:

\title{
Policy making during crises: how diversity and disagreement can help manage the politics of expert advice
}

\section{Alfred Moore and Michael K MacKenzie argue that greater openness about disagreement among diverse types of experts makes it harder for political leaders to politicise expertise}

\section{Alfred Moore, ${ }^{1}$ Michael K MacKenzie ${ }^{2}$}

Whenever scientists provide advice to political leaders they risk their expert authority being used in ways they cannot control in order to serve political ends. At one extreme, when they give unwelcome advice they risk being dismissed on the grounds that they must be taking sides. At the other extreme, expert authority can be used to shield political leaders from responsibility. The UK government, for example, has repeatedly insisted that it has simply been "following the science" when making decisions during the covid-19 pandemic, even though experts do not speak with one voice and scientific facts alone cannot determine how political (or ethical or moral) judgments should be made.

These two extreme responses-ostentatious dismissal of expert advice and ostentatious deference to it-work by denying the importance of legitimate disagreement and uncertainty. In the first case, disagreement is dismissed as being politically motivated. In the second, disagreement is masked altogether. Both temptations are strong when decision makers come under pressure, as they do during crisis situations.

While many have rightly focused on the ethos and duties of experts in political contexts, ${ }^{12}$ we focus on the role that political institutions can play in helping to manage the politics of expertise more effectively and legitimately. Drawing on findings from behaviour research, we identify two principles to guide the institutionalisation of expert advice. The first involves ensuring that diverse perspectives-both disciplinary and social-are adequately represented when expert advice is given and consulted. The second has to do with protecting, promoting, and normalising disagreement among diverse sets of experts.

\section{Inclusion of diverse perspectives}

Expert advice should draw on diverse disciplinary specialisms and diverse social perspectives. Disciplinary diversity is important for two reasons. Firstly, it can improve the quality of collective judgments and help avoid epistemic pitfalls. Among those pitfalls are the tendency for some experts to become "prisoners of their preconceptions" in a way that leads to poor predictions, a refusal to acknowledge mistakes, and dismissal of dissonant evidence. ${ }^{3}$ Another risk involves failing to recognise and question implicit shared assumptions, leading to incomplete examination of policies, selective bias in identifying and processing information, and inadequate consideration of alternatives. ${ }^{4}$ More positively, including diverse disciplinary perspectives can lead to better inferences and more accurate predictions. ${ }^{5}$ Inclusive deliberative processes can also help participants separate good arguments from bad ones and identify better solutions or more diverse options. $^{6}$

Secondly, the inclusion of diverse disciplinary perspectives can help legitimise political decisions and encourage public compliance with rules and regulations. Diverse groups are better able to identify affected - or potentially affected - interests and show how those interests may be adequately addressed when policy decisions are made. Unlike experts who must make issue specific recommendations based on their own expertise, political leaders must balance many different, often irreconcilable, interests against each other. If political leaders take advice from only certain types of experts they may not adequately consider (or even recognise) how diverse groups of people will be affected by their decisions.

During the covid-19 pandemic, political leaders in the United States and the United Kingdom have mainly relied on advice from medical experts (physicians, virologists, and epidemiologists), which is understandable during a health crisis. ${ }^{78}$ But advice from those experts should be considered alongside input from other types of experts such as economists, psychologists, sociologists, educators, and child welfare advocates. These (and other) experts are needed because the drastic actions that have been taken to limit the spread of the virus have consequences that reach well beyond the expertise of infectious disease specialists.

Diversity with respect to social knowledge, lived experiences, and perspectives ${ }^{9}$ is also important in the formation of expert advice. If those making judgments share certain characteristics, such as gender, age, race, home ownership, or wealth, they may fail to recognise how the costs of policies (such as stay-at-home orders) are likely to affect those who do not share those characteristics; they might recognise those costs and consider them to some extent but they will not feel those consequences of their decisions. The inclusion of diverse disciplinary and social perspectives can therefore help sharpen a sense of the stakes, which can, in turn, appropriately inform political judgment.

\section{Open disagreement}

The epistemic and political benefits of disciplinary diversity are widely recognised, if not always practised. The case for open disagreement among experts-especially during crises-is more often 
resisted. In the UK, the Scientific Advisory Group for Emergencies (SAGE), for instance, includes people from many different disciplinary backgrounds, but its membership was initially kept secret.

The assumption is that experts giving public policy advice should not be open about their uncertainties: they need to project certainty and unanimity in order to maintain authority and trust in the eyes of the public. The evidence, however, suggests otherwise. A recent study found that providing people with precise, numerical estimates of uncertainty increased their awareness of the uncertainties in public policy decisions on topics such as climate change and immigration but did not lead to any appreciable reductions in levels of public trust or increased mistrust of the sources of the information. ${ }^{10}$

There are both epistemic and political reasons to encourage open, adversarial exchanges among diverse experts in policy making processes. From an epistemic perspective, diversity is not sufficient to develop and test strong arguments. Experts, like the rest of us, need to have their arguments challenged if they are to avoid the cognitive pitfalls associated with overconfidence. Disagreements among experts (and others) can help draw out implicit value commitments, disciplinary assumptions, and blind spots.

Disagreement-even if it is only for the sake of disagreement-can also help support the thorough exploration of rival positions. This idea, which was famously advanced by the philosopher John Stuart Mill, finds support in recent research in behavioural science suggesting that adversarial argument helps diverse groups do a better job of evaluating arguments both for and against given propositions. ${ }^{11}$

Open disagreement also has at least two positive political functions. It can make it harder for political leaders to blur the lines between expert advice and political judgments. Political leaders considering, say, whether to mandate the wearing of face masks, will find it harder to use experts as a shield for unpopular decisions when the rationales and justifications behind expert disagreements-about, for instance, the assumptions used in modelling the effects of face masks on rates of transmission-are made public.

Being open about disagreements among experts, and the levels of uncertainty that their judgments entail, can also help political leaders to reverse course when necessary without seeming like they are being inconsistent or capitulating to political and thus unscientific demands. When political leaders openly discuss counterarguments and acknowledge the legitimacy of minority judgments, it helps keep alive reasons both for and against particular decisions, and this can make it easier for political leaders-and the public they serve-to justify revising or reversing previous policy decisions. ${ }^{12}$ The possibility of justifying policy reversals is important at the best of times, but it is crucial during rapidly evolving crises such as the covid-19 pandemic that are characterised by deep uncertainties.

\section{Separating politics from advice}

There are several ways that these two principles might be institutionalised, departing less or more substantially from established practices. Within existing expert committee structures, one option would be to introduce minority reports. Rather than publishing committee deliberations, which could make experts reluctant to express themselves honestly and increase the likelihood of inaccurate information being disseminated, expert committees might be required to publish carefully crafted statements from different minority perspectives. In this way, reasons both for and against particular pieces of policy advice could be made public but the risks of misinterpretation and misrepresentation would be minimised.

Another option would be for experts to form collective judgments by voting. Expert committees of the US National Institutes of Health, for instance, have held votes on whether a substance can be reasonably considered to be a carcinogen, and these processes have revealed disciplinary differences in judgments about risk. ${ }^{13}$ Public debates and voting among experts would help communicate disagreements where they exist, reveal disciplinary tendencies (or biases), and keep potentially credible counterarguments alive in policy processes, all while helping to filter out less credible or extreme claims or considerations.

Another option would take the selection of relevant experts out of the hands of political leaders or executives by adopting standing committees of experts, using legislative assemblies as a model. Such committees would comprise experts from many different disciplines, and their deliberations and voting processes would be public.

Political leaders are typically free to choose to listen to whichever experts they wish, and this often limits the diversity of the expertise they seek and receive. A standing committee of experts would help solve this problem by empowering diverse and independent experts to speak and influence political leaders and the public before any situations arise where their expertise may be needed. In this model, the experts would decide whether they have relevant expertise in any particular situations, but in contrast to standing bodies designed to report expert consensus, ${ }^{14}$ this body would serve to pluralise credible expert input.

A third option would be to encourage competing groups of experts to contribute to policy debates in structured or organised ways. Many experts have provided advice during the covid-19 pandemic, but we have little idea of their influence or how different (often competing) pieces of advice should be weighed against each other. A tribunal model could make these processes more cohesive. Rival experts would be empowered to question each other directly before an audience of experts from both within and outside their own specialties. ${ }^{15}$ Expert claims might also be adversarially examined before lay people, following the model of 19th century coroner's courts in the UK. ${ }^{16}$ This approach would help ensure that policy advice is sufficiently sensitive to the diverse lived experiences of affected populations.

\section{Conclusion}

Creating institutions that establish norms and expectations of legitimate disagreement as part of the process of forming and communicating expert advice would make it easier for experts to stay true to their expertise and harder for politicians to hide their judgments behind the science. The principles and institutions we have discussed are, of course, not a magic bullet: their effectiveness will depend to a large extent on the political environments into which expert advice is inserted. At the same time, they would help make those political environments more receptive to expert advice by minimising the opportunities that political leaders have to distort that advice or simply defer to it for their partisan purposes. Our proposals can thus be seen as a step towards enhancing the quality of public deliberation and, ultimately, political judgment, in our political systems by encouraging an attitude not of blind deference to the science but of allegiance to the norms of science itself: a respect for diversity of opinion and the value of disagreement in processes of inquiry. 


\section{Key messages}

- Political leaders drawing on expertise in a crisis face two temptations: to dismiss unwelcome expert claims as politically motivated and to mask expert disagreement

- Protecting and promoting open disagreement among diverse sets of expert advisers can improve the quality of advice

- It also makes it harder for political leaders to blur the lines between expert advice and political judgments

- Incorporating legitimate disagreement into the design of expert committees can improve decisions and manage the politics of expert advice

Contributors and sources: This article draws on social scientific research on deliberation and collective decision making to suggest ways of reforming expert advice in political contexts. AM, the lead contributor and guarantor of the article, has published widely in political theory and public understanding of science. MKMacK has published widely in democratic theory and institutional design. The authors have contributed equally to the development of this article.

Competing interests: We have read and understood BMJ policy on declaration of interests and have no relevant interests to declare.

Provenance and peer review: Not commissioned; externally peer reviewed.

We thank Michael Goodhart, Andrew Lotz, Anna Alexandrova, and Stephen John for their comments on an earlier version of this article.

1 Pielke RAJr. The honest broker: making sense of science in policy and politics. Cambridge University Press, 2007, doi: 10.1017/CB09780511818110

2 Horton R. How can any scientists stand by this government now? Guardian 2020 May 27. https:/www.theguardian.com/commentisfree/2020/may/27/scientists-ministers-dominic-cummings-advisers-government-coronavirus

3 Tetlock P. Expert political judgment: How good is it? How can we know? Princeton University Press, 2005: 163.

4 Sunstein CR. Going to extremes: how like minds unite and divide. Oxford University Press, 2009: 84.

5 Page SE. The difference: How the power of diversity creates better groups, firms, schools, and societies. Princeton University Press, 2008, doi: 10.1515/9781400830282.

6 Landemore H. Democratic reason: politics, collective intelligence, and the rule of the many. Princeton University Press, 2013: 96.

7 Facher L. A number of new stars: the definitive guide to the Trump administration's coronavirus response team. STAT 2020 Mar 20. https://www.statnews.com/2020/03/20/guide-to-trumpadministration-coronavirus-response-team/

8 Sample I. Who's who on secret scientific group advising UK government? Guardian 2020 Apr 28. https://www.theguardian.com/world/2020/apr/24/coronavirus-whos-who-on-secret-scientific-group-advising-uk-government-sage

9 Bohman J.Deliberative democracy and the epistemic benefits of diversity. Episteme (Edinb) 2006;3:175-91doi: 10.3366/epi.2006.3.3.175.

10 van der Bles AM, van der Linden S, Freeman AL,, Spiegelhalter DJ. The effects of communicating uncertainty on public trust in facts and numbers. Proc Natl Acad Sci U S A 2020;117:7672-83. doi: 10.1073/pnas.1913678117 pmid: 32205438

11 Mercier $\mathrm{H}$, Sperber D. Why do humans reason? Arguments for an argumentative theory. Behav Brain Sci2011;34:57-74, discussion 74-111. doi: 10.1017/S0140525X10000968 pmid: 21447233

12 Beatty J, Moore A. Should we aim for consensus? Episteme (Edinb) 2010;7:198-214doi: 10.3366/epi.2010.0203.

13 Guston D. On consensus and voting in science: From asilomar to the national toxicology program. In: Frickel S, Moore K, eds. The new political sociology of science. University of Wisconsin Press, 2005:378-404.

14 Collins H, Evans R. Why democracies need science. Polity Press, 2013: 84-6.

15 Turner S. Liberal democracy 3.0: Civil society in an age of experts. SAGE Publications, 2003: 125.

16 Pamuk Z. The people vs the experts: a productive struggle? In: Moore A, Invernizzi-Accetti C, Markovits E, Pamuk Z, Rosenfeld S, eds. Beyond populism and technocracy: the challenges and limits of democratic epistemology. Contemp Polit Theory2020.doi: 10.1057/s41296-020-00398-1.

This article is made freely available for use in accordance with BMJ's website terms and conditions for the duration of the covid-19 pandemic or until otherwise determined by BMJ. You may use, download and print the article for any lawful, non-commercial purpose (including text and data mining) provided that all copyright notices and trade marks are retained. 